\title{
Phase 1 study of darolutamide (ODM-201): a new-generation androgen receptor antagonist, in Japanese patients with metastatic castration-resistant prostate cancer
}

\author{
Nobuaki Matsubara $^{1} \cdot$ Hirofumi Mukai $^{1} \cdot$ Ako Hosono $^{1} \cdot$ Mai Onomura $^{1}$. \\ Masaoki Sasaki $^{1} \cdot$ Yoko Yajima $^{2} \cdot$ Kensei Hashizume $^{3} \cdot$ Masanobu Yasuda $^{4}$. \\ Miho Uemura $^{3} \cdot$ Christian Zurth $^{5}$
}

Received: 31 July 2017 / Accepted: 3 August 2017 / Published online: 11 August 2017

(C) The Author(s) 2017. This article is an open access publication

\begin{abstract}
Purpose This trial assessed the safety, pharmacokinetics, and efficacy of darolutamide (ODM-201), a new-generation nonsteroidal androgen receptor antagonist, in Japanese patients with metastatic castration-resistant prostate cancer (mCRPC).

Methods In this open-label, nonrandomized, two-cohort, dose-escalating phase 1 study, Japanese patients with mCRPC were enrolled after a screening period. In the single-dose period $(\approx 1$ week), darolutamide was administered at $300 \mathrm{mg}$ (Cohort 1) or $600 \mathrm{mg}$ (Cohort 2) on day -5 (fasting state) and day -2 (fed condition). In the subsequent
\end{abstract}

The original version of this article was revised: The author would like to correct the errors in the Affiliation of Masanobu Yasuda; In abstracts, second sentence of the method sections; Introduction section; In method section, the first sentence of the second paragraph; First paragraph of "Antitumor efficacy assessments" section and "Safety and tolerability" section; Table 1; Table 2; Table 3; Discussion section; Funding section and Reference section.

Electronic supplementary material The online version of this article (doi:10.1007/s00280-017-3417-3) contains supplementary material, which is available to authorized users.

Nobuaki Matsubara

nmatsuba@east.ncc.go.jp

1 Division of Breast and Medical Oncology, National Cancer Center Hospital East, 6-5-1 Kashiwanoha, Kashiwa, Chiba, Japan

2 Clinical Development, Bayer Yakuhin, Osaka, Japan

3 Clinical Sciences Japan, Bayer Yakuhin, Osaka, Japan

4 Clinical Statistics, Bayer Yakuhin, Osaka, Japan

5 Clinical Pharmacology Oncology, Bayer AG, Berlin, Germany multiple-dose period (fed condition), patients received darolutamide $300 \mathrm{mg}$ twice daily (Cohort 1 ) or $600 \mathrm{mg}$ twice daily (Cohort 2) for 12 weeks. Primary endpoints: evaluate safety and pharmacokinetics of darolutamide.

Results Of 12 patients enrolled, 9 received darolutamide (Cohort 1, $n=3$; Cohort 2, $n=6$ ). All 9 patients experienced $\geq 1$ treatment-emergent adverse event (TEAE; majority Grade 1/2). Incidence of drug-related TEAEs (DR-TEAEs) was $44 \%$ (all grades; $n=4$ ); most common DR-TEAE was decreased appetite (22\%), and 1 serious DR-TEAE (Grade 3 nausea) was observed. No Grade $\geq 4$ DR-TEAEs or new safety signals were observed. $C_{\max }$ and AUC $\left(0-t_{\text {last }}\right)$ were dose-dependent; pharmacokinetics of each dose appeared to be linear over time. Prostate-specific antigen response was observed in $11 \%$ (1/9) of patients. Compared with fasting status, geometric mean $C_{\max }$ increased 2.5 -fold after $300 \mathrm{mg}$ and 2.8-fold after $600 \mathrm{mg}$; geometric mean AUC (0- $\left.t_{\text {last }}\right)$ increased 2.5-fold after both doses under fed conditions.

Conclusions Darolutamide was well tolerated at the examined doses in Japanese patients with mCRPC, without differences in safety and pharmacokinetics relative to Western patients.

Keywords ODM-201 - Darolutamide · Androgen receptor antagonist Pharmacokinetic $\cdot$ Phase $1 \cdot$ Prostate cancer

\section{Introduction}

The global incidence of prostate cancer (PC) is approximately 1.1 million new cases per year, which accounts for $15 \%$ of all cancer cases in men [1], including Japanese men [2]. Based on the most recent estimates for Japan, there were 73,145 PC diagnoses in 2012 (incidence rate, 117.0 per 
100,000) and 11,507 PC-related deaths in 2014 (mortality rate, 18.9 per 100,000) [3]. In Japan, PC is among the most common cancer types in men and the sixth highest cause of cancer-related death $[2,4]$.

Initially, $\mathrm{PC}$ is an androgen-dependent disease and will respond to androgen deprivation therapy (ADT); however, almost all patients become resistant to ADT over time and develop castration-resistant PC [5], defined as increasing prostate-specific antigen (PSA) levels despite castrate levels of testosterone or the progression of preexisting disease with or without metastases. Patients who have PC that has progressed to advanced metastatic disease with castration resistance have a poor prognosis, with median survival times historically in the range of 1-2 years, although longer durations extending to $\sim 3$ years have been reported in recent clinical trials [6-9].

Androgen receptor (AR) antagonists are nonsteroidal antiandrogen agents that bind to ARs and inhibit the androgen-induced activation of these receptors, which ultimately inhibits tumor growth and proliferation. These agents have demonstrated efficacy in patients with metastatic castrationresistant PC (mCRPC) [10-12].

Darolutamide (formerly ODM-201) is a new-generation nonsteroidal AR antagonist with a unique molecular structure. It comprises a mixture of two diastereomers, $(S, R)$-darolutamide (ORM-16497) and $(S, S)$-darolutamide (ORM-16555), which interconvert via the major metabolite keto-darolutamide (ORM-15341) preferentially to $(S, S)$ darolutamide; all three compounds show similar pharmacologic activity [13-15]. In preclinical trials, darolutamide demonstrated higher binding affinity compared with other AR antagonists (such as bicalutamide and enzalutamide), an antiproliferative effect and tumor growth inhibition in ARoverexpressing cells, and activity against AR mutants linked to drug resistance. In addition, darolutamide is different from other new-generation nonsteroidal AR antagonists with respect to its negligible blood-brain barrier penetration [14-16]. In early phase clinical trials with Western mCRPC patients, darolutamide has shown a good safety profile and significant reductions in PSA levels [13, 17-19].

The aim of this phase 1 trial was to assess the safety and tolerability, pharmacokinetics (PK), and antitumor activity of darolutamide in Japanese patients with mCRPC (ClinicalTrials.gov identifier: NCT02363855).

\section{Methods}

\section{Trial design}

This was an open-label, nonrandomized, two-cohort, doseescalating phase 1 study. After a screening period (up to 4 weeks), patients entered a single-dose period ( 1 week), followed by a multiple-dose period (12 weeks) and a followup period (4 weeks) (Fig. 1). The primary endpoints were to determine the maximum tolerated dose and evaluate doselimiting toxicities, which were assessed by the number and intensity of all treatment-emergent adverse events (TEAEs) of darolutamide in Japanese patients with mCRPC. A secondary endpoint was to determine the PK parameters of darolutamide, diastereomers, $(S, R)$-darolutamide and $(S, S)$-darolutamide, and the major metabolite keto-darolutamide. Additional endpoints were to assess the efficacy and pharmacodynamics of darolutamide and explore the effect of food on PK.

In the single-dose period, darolutamide was administered in the fasting state on day -5 and after a usual Japanese breakfast (fed condition) on day -2 as two 150-mg tablets (300-mg dose; Cohort 1) or as four 150-mg tablets (600-mg dose; Cohort 2). Within 2 days of the single-dose period, patients were moved to the multiple-dose period, which

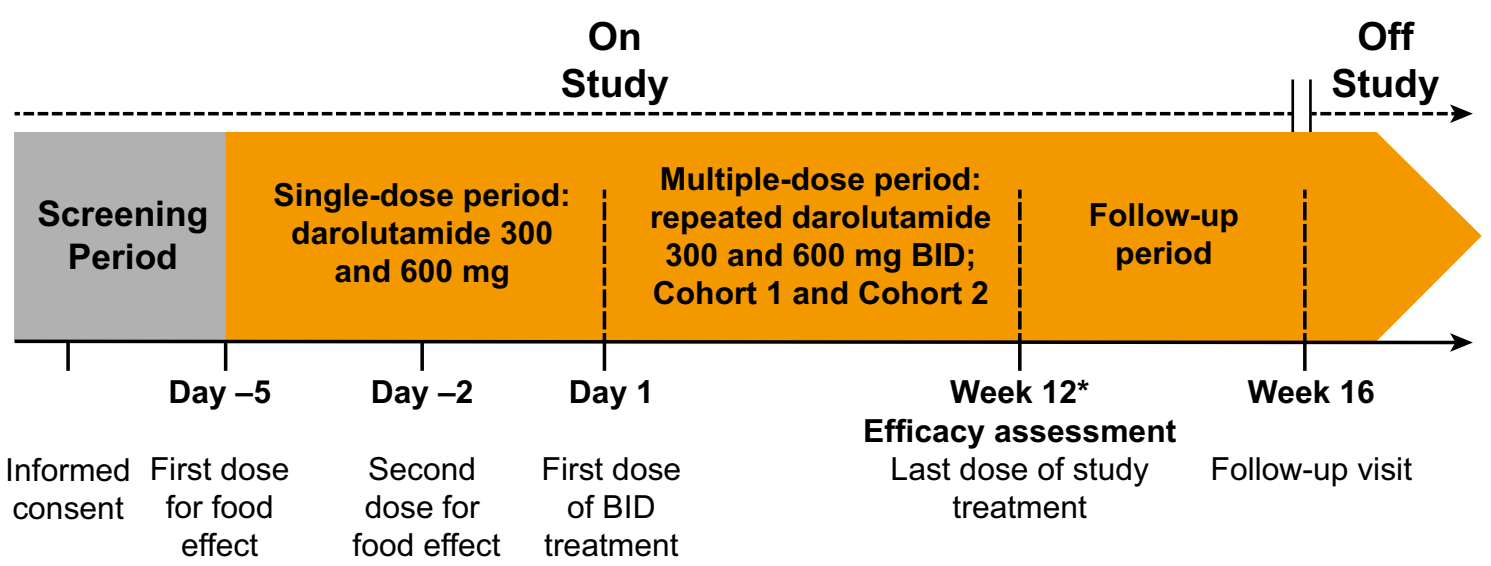

Fig. 1 Study design. If the investigator judged that treatment with darolutamide could be continued on the current dose after the multiple-dose periods, then patients could receive darolutamide until they met one of the criteria for withdrawal. BID twice daily 
consisted of two dose levels. The starting dose was $300 \mathrm{mg}$ (Cohort 1) followed by $600 \mathrm{mg}$ (Cohort 2). Cohort 2 initiated therapy based on the clinical safety evaluation after the last patient in Cohort 1 completed the 28-day period of the multiple-dose period. Patients could be added to Cohort 1 to evaluate safety and tolerability as needed. In the multipledose period, Cohort 1 received $300 \mathrm{mg}$ twice daily (BID; total daily dose, $600 \mathrm{mg}$ ) and Cohort 2 received $600 \mathrm{mg}$ BID (total daily dose, $1200 \mathrm{mg}$ ) on days 1-28. Darolutamide was given orally BID with breakfast and dinner. Treatment continued on the current dose until disease progression, intolerable toxicities, or consent withdrawal. A follow-up examination was conducted approximately 4 weeks after the end of study treatment.

\section{Patients}

Japanese patients aged $\geq 20$ years were eligible if they had mCRPC, defined as ongoing ADT with a luteinizing hormone-releasing hormone analogue or antagonist, or bilateral orchiectomy, and castrate level of serum testosterone $[<1.7 \mathrm{nmol} / \mathrm{L}(50 \mathrm{ng} / \mathrm{dL})]$ at screening and radiographic progressive disease or PSA increase of three consecutive rises, at least 1 week apart and PSA $>2 \mathrm{ng} / \mathrm{mL}$ at screening; Eastern Cooperative Oncology Group performance status (ECOG PS) of $0-1$; and prior treatment history with an antiandrogen for mCRPC. Patients with and without previous docetaxel-based chemotherapy were eligible for study entry. Patients were excluded if they had known brain metastases; any prior treatment for mCRPC within 4 weeks before study drug administration; use of bicalutamide within 6 weeks before the first dose of darolutamide; use of systemic corticosteroid with dose greater than the equivalent of $10 \mathrm{mg} /$ day prednisone within 4 weeks before the first dose of darolutamide; or initiation of bisphosphonate or denosumab therapy within 4 weeks before the first drug administration.

\section{Ethics}

All patients gave written informed consent for participation in the study. The study was approved by the study site's institutional review board (National Cancer Center Institutional Review Board, Japan) and conducted in accordance with the principles of the Declaration of Helsinki and the International Council for Harmonisation guideline E6: Good Clinical Practice and applicable regulatory requirements.

\section{Pharmacokinetic assessments}

Blood samples were taken predose and at $0.5,1,1.5,3,5$, $8,12,24,36$, and 48 -h postdose on day- 5 and day- 2 in the single-dose period, and predose and at $0.5,1,1.5,3,5,8$, and 12 -h postdose on day 7 in the multiple-dose period. Plasma concentrations of diastereomers $(S, R)$-darolutamide and $(S, S)$-darolutamide and the major metabolite keto-darolutamide were determined using a validated high-performance liquid chromatography with tandem mass spectrometric detection (LC-MS/MS) method. PK parameters were calculated using WinNonlin software (version 5.3; Pharsight Corporation, Mountain View, CA, USA) in conjunction with the Automation Extension (Bayer AG).

\section{Antitumor efficacy assessments}

Antitumor efficacy was assessed by PSA response, which is defined as percentage change of PSA at week 12 from baseline; tumor response was defined in accordance with the recommendations of the Prostate Cancer Clinical Trials Working Group 2 (PCWG2) [20] and Response Evaluation Criteria in Solid Tumors (RECIST) 1.1 [21]. Blood samples for PSA levels were collected at screening, once during the single-dose period (predose on day -5 or day -6 ; mean defined the baseline value), at three time points during the multiple-dose period (weeks 4,8 , and 12), at the end of treatment, and at the follow-up. For patients with a PSA decline from baseline at week 12, PSA progression was defined as the date of documented PSA increase $\geq 25 \%$ and absolute increase $\geq 2 \mathrm{ng} / \mathrm{mL}$ above the nadir, which was to be confirmed by a second value obtained $\geq 3$ weeks later. For patients without a PSA decline from baseline at week 12, PSA progression was defined as the date of documented PSA increase $\geq 25 \%$ along with an absolute increase from baseline $\geq 2 \mathrm{ng} / \mathrm{mL}$, which was to be confirmed by a second value obtained $\geq 3$ weeks later.

Radiologic assessment [magnetic resonance imaging/ computed tomography (CT)] of metastatic soft-tissue lesions was performed on all suspected sites of disease and evaluated locally at the study site using RECIST 1.1 criteria. Soft-tissue lesions were imaged using CT scans at screening and within 1 week before the last visit in the multiple-dose period. RECIST 1.1 criteria were used for the evaluation of disease progression. Bone metastases were assessed by radionuclide bone scintigraphy (bone scans) with ${ }^{99 \mathrm{~m}} \mathrm{Tech}$ netium $\left({ }^{99 \mathrm{~m}} \mathrm{Tc}\right)$ at screening and within 1 week before the last visit in the multiple-dose period.

\section{Safety and tolerability}

Safety evaluations were performed until week 12 and included results of physical examinations, 12-lead electrocardiogram (ECG), Holter ECG, vital signs (blood pressure, pulse rate, and body temperature), body weight, adverse events (AEs), and laboratory examinations. All AEs were graded using the National Cancer Institute Common 
Terminology Criteria for Adverse Events, version 4.03 (NCI CTCAE v4.03). Laboratory examinations were performed at screening; predose on day -5 or day -6 , day -2 , and day 1 ; at day 7 before breakfast; at each subsequent visit during the multiple-dose period; at the end of treatment; and at the follow-up/discontinuation.

\section{Statistical analysis}

The safety analysis set was defined as all patients who received $\geq 1$ dose of darolutamide, the full analysis set was defined as all patients who were assigned to study treatment, and the PK analysis set was defined as all patients who had valid PK data. No formal statistical sample size estimation was performed, because this phase 1 trial is standard phase $1,3+3$ design of toxicity assessment.
Statistical evaluation was performed using SAS release 9.2 or higher (SAS Institute Inc., Cary, NC, USA). All variables were analyzed by descriptive statistics. For PK parameters, arithmetic mean, SD and coefficient of variation $(\mathrm{CV})$, geometric mean (GM), geometric SD (re-transformed SD of the logarithms) and CV; minimum, median, maximum values; and the number of measurements were calculated for darolutamide, diastereomers $(S, R)$-darolutamide and $(S, S)$ darolutamide, and major metabolite keto-darolutamide. Individual and GM concentration versus time curves were plotted by cohort using both linear and semilogarithmic scales. PK parameters of time to maximum observed drug concentration $\left(t_{\max }\right)$ and time of the last data point greater than the lower limit of quantitation $\left(t_{\text {last }}\right)$ were described using minimum, maximum, and median as well as frequency counts. For maximum observed drug concentration $\left(C_{\max }\right)$ and area
Fig. 2 Patient disposition (all patients, cut-off date: May 9, 2016)

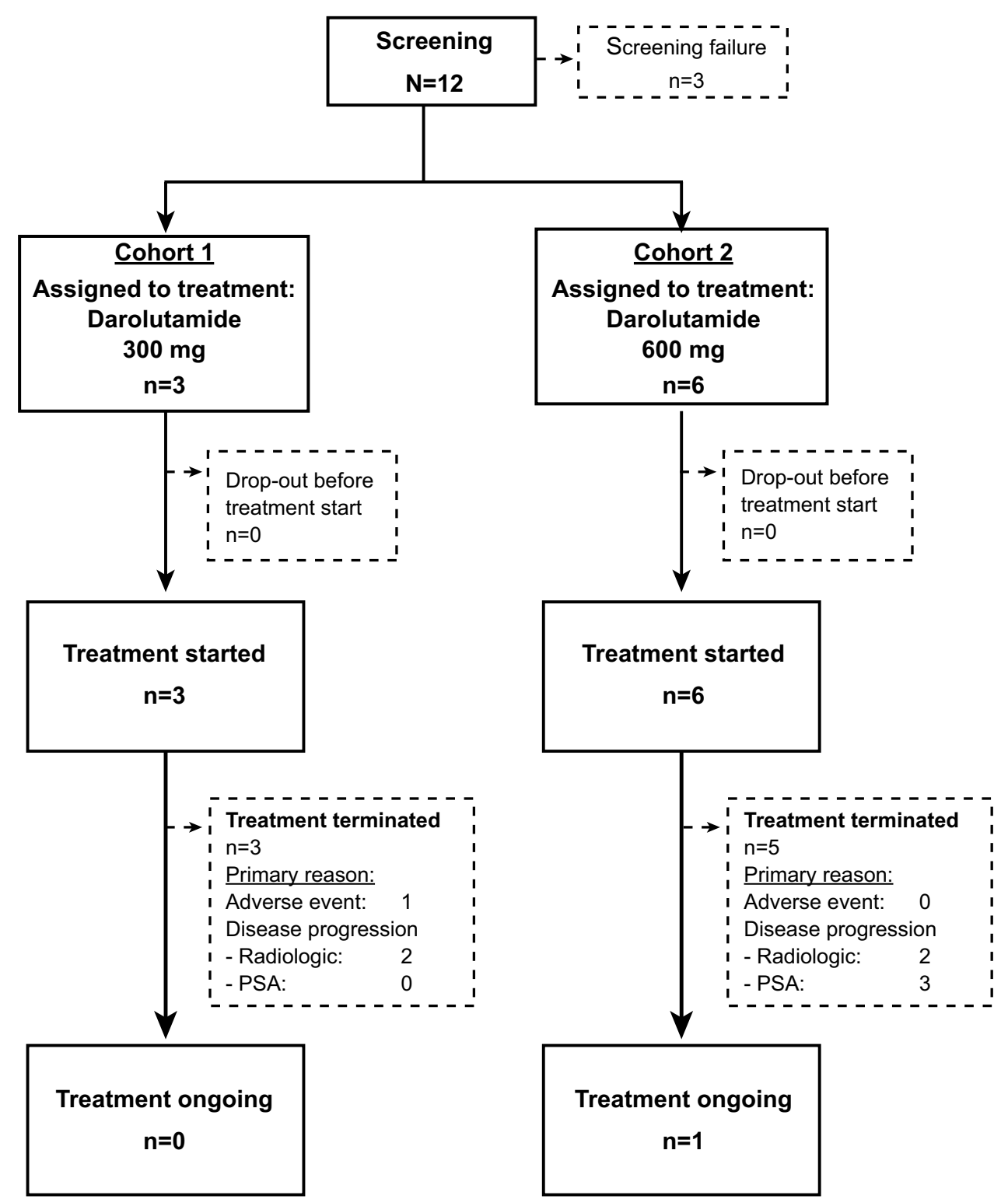


under the concentration versus time curve (AUC), $90 \%$ confidence interval for the GM ratio (fed/fast) was calculated.

\section{Results}

\section{Patient disposition and demographics}

Patient disposition is shown in Fig. 2. Of the 12 patients enrolled, nine were assigned to receive darolutamide: three patients received darolutamide $300 \mathrm{mg}$ (Cohort 1), and six received darolutamide $600 \mathrm{mg}$ (Cohort 2). All nine patients received two single doses of darolutamide in the single-dose period and then started multiple-dose treatment on day 1 of the multiple-dose period. At the time of data cut (May 9, 2016), 8 of 9 (89\%) patients had terminated multipledose treatment and completed the safety follow-up, and 1 patient (11\%) had continued treatment with darolutamide without disease progression. Treatment discontinuation was primarily due to disease progression (four patients had radiologic progression, and three had PSA progression).

Demographic and baseline characteristics are presented in Table 1. Overall, the median (range) age of the nine male Japanese patients was 70.0 (64-83) years; median body mass index was 23.2 (range $20-28) \mathrm{kg} / \mathrm{m}^{2}$, and median PSA level was 39 (range 5-290) $\mu \mathrm{g} / \mathrm{L}$. Mean Gleason score was 8 . All patients had an ECOG PS of 0-1. All nine patients had received prior hormonal therapy for $\mathrm{mCRPC}$; four patients received chemotherapy.

Median percentage of patients who received the planned dose of darolutamide was $99.2 \%$ (range $98-100 \%$ ) for the 300-mg BID dose and $99.6 \%$ (range 73-100\%) for darolutamide $600-\mathrm{mg}$ BID dose. Mean percentage of patients who received the planned dose of darolutamide was slightly higher in the 300-mg BID dose cohort (99.2\%) versus the 600-mg BID dose cohort (95.2\%), because 1 patient in the latter dose cohort had a lower compliance of $73 \%$. Mean
Table 1 Demographics and patient characteristics

\begin{tabular}{|c|c|c|c|}
\hline & $\begin{array}{l}\text { Cohort } 1 \\
300 \mathrm{mg} \text { BID } \\
n=3\end{array}$ & $\begin{array}{l}\text { Cohort } 2 \\
600 \mathrm{mg} \text { BID } \\
n=6\end{array}$ & $\begin{array}{l}\text { Total } \\
N=9\end{array}$ \\
\hline Median (range) age, years & $68.0(67-73)$ & $73.0(64-83)$ & $70.0(64-83)$ \\
\hline Mean (SD) age & $69.3(3.2)$ & $73.7(7.6)$ & $72.2(6.6)$ \\
\hline Median (range) weight, $\mathrm{kg}$ & $61.9(59-69)$ & $58.9(53-77)$ & $61.9(53-77)$ \\
\hline Median (range) height, $\mathrm{cm}$ & $165.5(163-170)$ & $158.7(152-170)$ & $162.8(152-170)$ \\
\hline $\begin{array}{l}\text { Median (range) body mass index, } \\
\mathrm{kg} / \mathrm{m}^{2}\end{array}$ & $23.4(20-25)$ & $23.0(21-28)$ & $23.2(20-28)$ \\
\hline Median (range) PSA, $\mu \mathrm{g} / \mathrm{L}$ & $61(39-290)$ & $32(5-260)$ & $39(5-290)$ \\
\hline Mean (SD) PSA & $130(139)$ & 99 (118) & 109 (117) \\
\hline \multicolumn{4}{|l|}{ ECOG PS, $n(\%)^{\mathrm{a}}$} \\
\hline 0 & $2(66.7)$ & $4(66.7)$ & $6(66.7)$ \\
\hline 1 & $1(33.3)$ & $2(33.3)$ & $3(33.3)$ \\
\hline \multicolumn{4}{|l|}{ EOD at screening, $n(\%)^{\mathrm{b}}$} \\
\hline 0 & $1(33.3)$ & 0 & $1(11.1)$ \\
\hline 1 & 0 & 0 & 0 \\
\hline 2 & $1(33.3)$ & $2(33.3)$ & $3(33.3)$ \\
\hline 3 & $1(33.3)$ & $4(66.7)$ & $5(55.6)$ \\
\hline 4 & 0 & 0 & 0 \\
\hline \multicolumn{4}{|l|}{ Prior therapy, $n(\%)$} \\
\hline Chemotherapy/hormonal & $1(33.3) / 3(100.0)$ & $0(0) / 6(100.0)$ & $1(11.1) / 9(100.0)$ \\
\hline Docetaxel & $2(66.7)$ & $2(33.3)$ & - \\
\hline Abiraterone & $2(66.7)$ & $3(50.0)$ & - \\
\hline Enzalutamide & $3(100.0)$ & $3(50.0)$ & - \\
\hline
\end{tabular}

$B I D$ twice daily, ECOG PS Eastern Cooperative Oncology Group performance status, EOD extent of disease, $P S A$ prostate-specific antigen

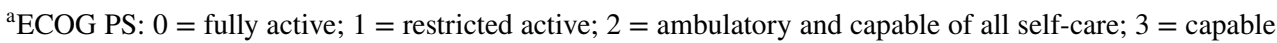
of limited self-care; $4=$ completely disabled

${ }^{\mathrm{b}}$ EOD (bone scan findings/evaluation of bone metastases): $0=$ normal or abnormal because of benign bone disease; $1=<6$ metastatic sites; $2=6-20$ metastatic sites; $3=>20$ lesions but not a superscan; $4=$ superscan (i.e., $>75 \%$ of the ribs, vertebrae, and pelvic bones) 
(SD) actual daily dose of darolutamide was 595.1 (4.8) $\mathrm{mg}$ in Cohort 1 and 1142.9 (129.5) $\mathrm{mg}$ in Cohort 2.

\section{Pharmacokinetic assessment}

\section{Darolutamide (mixed diastereomers)}

Single-dose period Overall, median $t_{\max }$ was $3-6 \mathrm{~h}$ for darolutamide, demonstrating slow absorption; terminal half-life was in the range of 10-15 h. The PK parameters for darolutamide in the single-dose period under fasted and fed conditions are shown in Table 2. $C_{\max }$ and AUC $\left(0-t_{\text {las }}\right)$ values were higher with 600 versus $300 \mathrm{mg}$ under fasting and fed conditions. The CV for AUC $\left(0-t_{\text {last }}\right)$ was higher for $300 \mathrm{mg}(69.6 \%)$ versus $600 \mathrm{mg}(41.4 \%)$ and higher than those under fed conditions (20.1 and $24.0 \%$, respectively). Darolutamide achieved peak concentrations between 3 and $5 \mathrm{~h}$ postdose in the fasted state and between 3 and $8 \mathrm{~h}$ postdose in the fed state. In addition, $t_{\max }$ was observed later under fed versus fasting conditions (Supplemental Fig S1).

Under both fasted and fed conditions, dose-normalized values for $C_{\max }\left(C_{\max } / \mathrm{D}\right), \operatorname{AUC}(\mathrm{AUC} / \mathrm{D})$, and $\operatorname{AUC}\left(0-t_{\text {last }}\right)$ $\left(\mathrm{AUC}\left[0-t_{\text {last }}\right] / \mathrm{D}\right)$ showed no relevant differences between the
300- and 600-mg doses, although AUC/D and $C_{\max } / D$ tended to be lower for darolutamide $600 \mathrm{mg}$.

Administration of darolutamide as a single oral dose under fed conditions demonstrated that bioavailability of darolutamide was 2.5- and 2.8-fold higher (after 300 and $600 \mathrm{mg}$, respectively) versus darolutamide given in fasting conditions. Similarly, the AUC $\left(0-t_{\text {last }}\right)$ of darolutamide for the fed state was 2.5 -fold higher after 300 and $600 \mathrm{mg}$ compared with the fasting state (Supplemental Table S1).

Multiple-dose period Darolutamide demonstrated a relatively flat PK profile at steady state that was most likely associated with the short dosing interval and its terminal half-life (Supplemental Fig S1). The PK parameters for darolutamide in the multiple-dose period are shown in Table 3. On day 7 of the multiple-dose (md) period, darolutamide $C_{\max }$ was reached 3-11 $\mathrm{h}$ after the dose taken with breakfast, with median $t_{\text {max,md }}$ values of 4.98 and $5.48 \mathrm{~h}$ for $300 \mathrm{mg}$ BID and $600 \mathrm{mg}$ BID, respectively. Geometric mean $C_{\text {max,md }}$ values for darolutamide on day 7 were 4.60 and $5.80 \mu \mathrm{g} /$ $\mathrm{mL}$ for $300 \mathrm{mg}$ BID and $600 \mathrm{mg}$ BID, respectively, which is approximately 1.8 and 1.7 times higher versus $C_{\max }$ val-
Table 2 Summary of darolutamide pharmacokinetic parameters for the singledose period (fasting and fed conditions)

\begin{tabular}{|c|c|c|c|c|}
\hline Parameter & Dose (mg) & $n$ & $\begin{array}{l}\text { Day -5 (fasting) } \\
\text { Geom mean (CV\%) }\end{array}$ & $\begin{array}{l}\text { Day }-2(\text { fed }) \\
\text { Geom mean }(\mathrm{CV} \%)\end{array}$ \\
\hline \multirow[t]{2}{*}{ AUC, $\mu \mathrm{g} \cdot \mathrm{h} / \mathrm{mL}$} & 300 & 2 & $24.2(36.7)$ & $45.5(23.7)$ \\
\hline & 600 & 4 & $19.0(34.8)$ & $63.5(28.9)$ \\
\hline \multirow[t]{2}{*}{$\operatorname{AUC}\left(0-t_{\text {last }}\right), \mu \mathrm{g} \cdot \mathrm{h} / \mathrm{mL}$} & 300 & 3 & $15.7(69.6)$ & $39.0(20.1)$ \\
\hline & 600 & 6 & $22.0(41.4)$ & $55.6(24.0)$ \\
\hline \multirow[t]{2}{*}{$\operatorname{AUC}\left(0-t_{\text {last }}\right) / D, \mathrm{~h} / \mathrm{L}$} & 300 & 3 & $0.052(69.6)$ & $0.130(20.1)$ \\
\hline & 600 & 6 & $0.037(41.4)$ & $0.093(24.0)$ \\
\hline \multirow[t]{2}{*}{ AUC/D, h/L } & 300 & 2 & $0.081(36.7)$ & $0.152(23.7)$ \\
\hline & 600 & 4 & $0.032(34.8)$ & $0.106(28.9)$ \\
\hline \multirow[t]{2}{*}{$\mathrm{AUC}(0-12), \mu \mathrm{g} \cdot \mathrm{h} / \mathrm{mL}$} & 300 & 3 & $8.1(84.8)$ & $20.4(15.3)$ \\
\hline & 600 & 6 & $10.8(38.9)$ & $25.1(15.3)$ \\
\hline \multirow[t]{2}{*}{$\operatorname{AUC}(0-12) / D, \mathrm{~h} / \mathrm{L}$} & 300 & 3 & $0.027(84.8)$ & $0.068(15.3)$ \\
\hline & 600 & 6 & $0.018(38.9)$ & $0.042(15.3)$ \\
\hline \multirow[t]{2}{*}{$C_{\max }, \mu \mathrm{g} / \mathrm{mL}$} & 300 & 3 & $1.05(92.9)$ & $2.59(7.57)$ \\
\hline & 600 & 6 & $1.26(41.3)$ & $3.50(12.1)$ \\
\hline \multirow[t]{2}{*}{$C_{\max } / D, 1 / \mathrm{L}$} & 300 & 3 & $0.004(92.9)$ & $0.009(7.57)$ \\
\hline & 600 & 6 & $0.002(41.3)$ & $0.006(12.1)$ \\
\hline \multirow[t]{2}{*}{$\mathrm{t}_{1 / 2}, \mathrm{~h}$} & 300 & 2 & $15.2(2.84)$ & $14.8(16.4)$ \\
\hline & 600 & 4 & $10.1(21.2)$ & $14.1(36.7)$ \\
\hline \multirow[t]{2}{*}{$t_{\max }, \mathrm{h}$} & 300 & 3 & $3.05^{\mathrm{a}}\left(2.95-4.97^{\mathrm{b}}\right)$ & $4.92^{\mathrm{a}}\left(2.98-8.00^{\mathrm{b}}\right)$ \\
\hline & 600 & 6 & $4.85^{\mathrm{a}}\left(3.05-4.92^{\mathrm{b}}\right)$ & $6.29^{\mathrm{a}}\left(4.93-7.90^{\mathrm{b}}\right)$ \\
\hline
\end{tabular}

$A U C$ area under the concentration versus time curve, $A U C\left(0-t_{\text {last }}\right)$ AUC from time 0 to time of last data point, $C_{\max }$ maximum observed drug concentration, $C V \%$ geometric coefficient of variation, $D$ dose-normalized, $t_{1 / 2}$ half-life, $t_{\max }$ time to reach $C_{\max }$

${ }^{\mathrm{a}}$ Median

${ }^{\mathrm{b}}$ Range 
Table 3 Summary of darolutamide pharmacokinetic parameters for multiple-dose period (day 7)

\begin{tabular}{|c|c|c|c|}
\hline Parameter & $\begin{array}{l}\text { Dose, } \\
\text { BID (mg) }\end{array}$ & $n$ & Geom mean (CV\%) \\
\hline \multirow[t]{2}{*}{$\mathrm{AUC}_{\mathrm{tau}}(0-12)_{,_{\mathrm{md}}}, \mu \mathrm{g} \cdot \mathrm{h} / \mathrm{mL}$} & 300 & 3 & $44.4(18.2)$ \\
\hline & 600 & 6 & $58.7(26.9)$ \\
\hline \multirow[t]{2}{*}{$\mathrm{AUC}_{\text {tau }}(0-12) / \mathrm{D}_{\mathrm{md}}, \mathrm{h} / \mathrm{L}$} & 300 & 3 & $0.148(18.2)$ \\
\hline & 600 & 6 & $0.098(26.9)$ \\
\hline \multirow[t]{2}{*}{$C_{\text {max }, \operatorname{md}}, \mu \mathrm{g} / \mathrm{mL}$} & 300 & 3 & $4.60(10.3)$ \\
\hline & 600 & 6 & $5.80(22.0)$ \\
\hline \multirow[t]{2}{*}{$C_{\max } / D_{\mathrm{md}}, 1 / \mathrm{L}$} & 300 & 3 & $0.0153(10.3)$ \\
\hline & 600 & 6 & $0.0097(22.0)$ \\
\hline \multirow[t]{2}{*}{$R_{\mathrm{A}} \mathrm{AUC}$} & 300 & 3 & $2.18(26.0)$ \\
\hline & 600 & 6 & $2.34(27.8)$ \\
\hline \multirow[t]{2}{*}{$R_{\mathrm{A}} C_{\max }$} & 300 & 3 & $1.78(17.8)$ \\
\hline & 600 & 6 & $1.66(24.6)$ \\
\hline \multirow[t]{2}{*}{$R_{\mathrm{LIN}}$} & 300 & 2 & $0.910(4.56)$ \\
\hline & 600 & 4 & $0.961(13.9)$ \\
\hline \multirow[t]{2}{*}{$t_{\max , \operatorname{md}}, \mathrm{h}^{\mathrm{a}}$} & 300 & 3 & $4.98(3.00-8.10)$ \\
\hline & 600 & 6 & $5.48(2.87-10.9)$ \\
\hline
\end{tabular}

$A U C$ area under the concentration versus time curve, $C_{\max }$ maximum observed drug concentration, $C V$ geometric coefficient of variation, $D$ dose-normalized, $m d$ multiple dose, $R_{A}$ accumulation ratio, $R_{L I N}$ mean linearity factor, $t_{\max }$ time to reach $C_{\max }$

${ }^{a}$ Median (range)

ues achieved after 300- and 600-mg single doses under fed conditions (2.59 and $3.50 \mu \mathrm{g} / \mathrm{mL})$. Geometric mean AUC values for $\mathrm{AUC}_{\mathrm{tau}}(0-12)_{\mathrm{md}}$ were 44.4 and $58.7 \mu \mathrm{g} \mathrm{h} / \mathrm{mL}$ for darolutamide $300 \mathrm{mg}$ BID and $600 \mathrm{mg}$ BID, corresponding to a 1.3 -fold increase in exposure after multiple dosing with $600 \mathrm{mg}$ BID versus $300 \mathrm{mg}$ BID. Mean linearity factor $\left(\mathrm{R}_{\mathrm{LIN}}\right)$ was comparable between the doses $(0.910$ for $300 \mathrm{mg}$ $\mathrm{BID}, 0.961$ for $600 \mathrm{mg} \mathrm{BID})$. The dose-normalized parameter $C_{\text {max }} / D_{\text {md }}$ and $\mathrm{AUC}_{\mathrm{tau}}(0-12) / D_{\mathrm{md}}$ does not indicate any relevant differences between the 2 dose levels.

\section{Darolutamide diastereomers $\quad(S, R)$-darolutamide} and $(S, S)$-darolutamide Median $t_{\max }$ was shorter for diastereomer $(S, R)$-darolutamide versus diastereomer $(S, S)$ darolutamide at both darolutamide dose levels when administered as single or multiple doses (Supplemental Tables S2 for single dose and S3 for multiple doses). Exposure to diastereomer $(S, R)$-darolutamide was less versus diastereomer $(S, S)$-darolutamide. The ratio of diastereomer $(S, R)$-darolutamide $\mathrm{AUC}\left(0-t_{\text {last }}\right)$ to diastereomer $(S, S)$-darolutamide was approximately 1:4 (fasting) and 1:5 (fed) after a single dose of $300 \mathrm{mg}$, and approximately 1:7 (fasting) and 1:8 (fed) after a single dose of $600 \mathrm{mg}$.

Metabolite keto-darolutamide The $C_{\max }$ of major metabolite keto-darolutamide was higher compared with daroluta- mide at both the 300- and 600-mg dose levels when administered as either single or multiple doses (Supplemental Tables S2, S3). Exposure to metabolite keto-darolutamide was 1.28-fold (fasting) and 1.33-fold (fed) higher compared with darolutamide after a single dose of $300 \mathrm{mg}$, and 1.44fold (fasting) and 1.61-fold (fed) higher after a single dose of $600 \mathrm{mg}$. A similar food effect was observed for $C_{\max }$. Food had no effect on $t_{\max }$ (Supplemental Tables S2, S3).

\section{Safety}

All $9(100 \%)$ patients reported $\geq 1$ TEAE. Drug-related TEAEs were reported for 4 of $9(44 \%)$ patients: 2 patients each in Cohorts 1 and 2 . The 7 drug-related TEAEs reported in the study were Grade 3 nausea, Grade 2 vomiting, Grade 1 headache, Grade 1 decreased appetite (all 4 events reported for the same patient in Cohort 1), an additional case of Grade 1 decreased appetite (1 patient in Cohort 1), Grade 2 amylase increased (1 patient in Cohort 2), and Grade 1 pyrexia (1 patient in Cohort 2). Drug-related TEAEs of Grades 4 or 5 were not observed. Serious TEAEs were reported for 3 of $9(33 \%)$ patients: Grade 3 nausea (1 patient; $300 \mathrm{mg}$ BID), Grade 2 enterocolitis (1 patient; $300 \mathrm{mg}$ BID), and Grade 2 malaise (1 patient; $600 \mathrm{mg}$ BID). Only nausea was considered to be drug related. The frequency or severity of drug-related TEAEs and serious TEAEs did not increase with darolutamide $600 \mathrm{mg}$ BID versus $300 \mathrm{mg}$ BID.

There were no clinically relevant changes in vital signs or ECG. All laboratory evaluations were considered unrelated to study drug except for 1 patient who had an increase in amylase (Grade 2) treated with darolutamide $600 \mathrm{mg}$ BID. Darolutamide had no drug effect on serum concentrations of follicle-stimulating hormone (FSH), luteinizing hormone (LH), testosterone, or dihydrotestosterone (DHT).

\section{Efficacy}

\section{PSA kinetics}

In Cohort 1, mean PSA increased from $132.0 \mu \mathrm{g} / \mathrm{L}(n=3)$ at baseline to $276.6 \mu \mathrm{g} / \mathrm{L}$ at week $8(n=2)$ and then was $93.1 \mu \mathrm{g} / \mathrm{L}$ at week $12(n=1)$, which corresponded to a mean (SD) change of $84.8 \%$ (14.6\%; median change, $81.3 \%$ ) from baseline to week 12 (Supplemental Tables S4, S5). No PSA response was observed in Cohort 1. In Cohort 2, mean PSA increased from $97.0 \mu \mathrm{g} / \mathrm{L}(n=6)$ at baseline to $178.1 \mu \mathrm{g} / \mathrm{L}$ at week $12(n=5)$, which corresponded to a mean (SD) change of $55.2 \%$ (95.7\%; median change, $53.0 \%$; Supplemental Tables S4, S5). Changes in PSA demonstrated high interpatient variability as evidenced by a change from baseline to week 12 in PSA concentration that varied from +72.3 to $+100.9 \%$ in Cohort 1 , and from -84.6 to $+211.1 \%$ in Cohort 2 (Supplemental Table S5). Similarly, assessment of 
changes from baseline at any time during or after treatment demonstrated maximum decreases in PSA of $0.7 \%$ (Cohort 1) and $84.6 \%$ (Cohort 2) and maximum increases of $100.9 \%$ (Cohort 1) and 72.2\% (Cohort 2; Supplemental Table S5). Only 1 of 9 patients showed a PSA response (PSA decline $\geq 50 \%$ from baseline) at week 12 (600 mg BID cohort).

\section{RECIST and bone scan response}

At time of screening, six patients (67\%) had only bone metastases, $1(11 \%)$ had only visceral metastases, and 2 (22\%) had both bone and visceral metastases. None of the three patients evaluable for the assessment of soft-tissue involvement achieved complete response or partial response, one had stable disease, and two experienced progressive disease (Supplemental Table S6). None of the six patients who had only bone metastases achieved a complete or partial response.

The extent-of-disease (EOD) grades shown by ${ }^{99 \mathrm{~m}} \mathrm{Tc}$ bone scintigraphy performed at screening (baseline), visit 8 (week 12), and visit 14 (month 9) are reported in Supplemental Table S7. Bone scan results showed no progression of bone lesions in this study.

\section{Discussion}

This dose-escalating phase 1 study was the first clinical study to evaluate safety and PK of darolutamide in Japanese patients with mCRPC. Darolutamide administered as a single 300- or 600-mg once-daily dose (with and without food) or as multiple doses of $300 \mathrm{mg}$ BID or $600 \mathrm{mg}$ BID for a median treatment duration of 84 days (range 31-328) was well tolerated in this heavily treated population, and overall toxicities were consistent with the known safety profile of darolutamide in a previously reported phase 1 trial in a Western study population [13, 17].

Our results show that there are no remarkable differences in PK parameters between Japanese and Western patients with mCRPC [13, 17]. For example, Western patients in the ARAFOR study who were administered a single dose of darolutamide $600 \mathrm{mg}$ had $C_{\max }$ and $\mathrm{AUC}_{0-48}$ values approximately twofold greater in the fed versus fasted state compared with 2.8- and 2.5-fold greater in Japanese patients, and fed-state $t_{\max }$ values of 4.0 versus $6.3 \mathrm{~h}$, respectively [17]. Similar PK results were also observed in the ARADES study in which Western patients received a daily dose of 200-1800 mg of darolutamide. On day 1 , median $t_{\max }$ values were 3.0-5.1 and 1.5-5.0 $\mathrm{h}$ for darolutamide and ketodarolutamide, respectively. At steady state, mean half-life of darolutamide was $15.8 \mathrm{~h}$, independent of dose, and $10.0 \mathrm{~h}$ for keto-darolutamide [13]. Thus, there is no need for dose adjustment of darolutamide based on Japanese ethnicity.
Similar to the Western patient studies, a significant food effect was observed on the bioavailability of darolutamide in that absorption was slower in the fasted condition, and AUC and $C_{\max }$ were increased twofold along with a prolongation of $t_{\max }$ under fed conditions. As the current Japanese PK data support the PK findings observed in the previous Western patient population studies, these collective absorption and exposure data suggest that darolutamide should be taken with food. Finally, $C_{\max }$ and AUC $\left(0-t_{\text {last }}\right)$ of darolutamide increased by dose, while the accumulation ratios for darolutamide calculated from $C_{\max }\left(\mathrm{R}_{\mathrm{A}} C_{\max }\right)$ and $\mathrm{AUC}\left(\mathrm{R}_{\mathrm{A}} \mathrm{AUC}\right)$, as well as the $R_{\mathrm{LIN}}$ of PK after repeated administration of 300 and $600 \mathrm{mg}$, were comparable for the two tested doses, suggesting that the PK of each dose was linear over time.

All patients in this study had received prior systemic treatment for mCRPC, which likely affected the observed efficacy of darolutamide. A complete response or partial response was not reported at either dose level; however, seven patients had a history of extensive anticancer treatment that included new AR antagonist agents (abiraterone and enzalutamide) and/or chemotherapy (docetaxel and cabazitaxel). Similarly, only one patient achieved a PSA response (patient had a PSA decline $\geq 50 \%$ from baseline at week 12), which is not unexpected, considering that all patients had received previous therapy for mCRPC.

Similar to previous early phase clinical studies in mainly Western patients, most AEs were Grade 1-2 [13, 17], and drug-related TEAEs included vomiting, headache, decreased appetite, increased amylase, and pyrexia. Only 1 serious TEAE (Grade 3 nausea) was considered drug related. All laboratory toxicities were considered unrelated to darolutamide treatment except for amylase increase in one patient (600 mg BID). ECG findings were not clinically significant, and darolutamide had no observed effect on FSH, LH, testosterone, or DHT concentrations. Overall, a dose-dependent increase in the frequency or severity of AEs was not observed. Our results confirmed that darolutamide has a favorable toxicity profile in Japanese mCRPC patients.

A limitation of the study is that any prior systemic anticancer therapy was allowed, confounding evaluation of efficacy in this heavily pretreated patient population; it is not known whether the main objectives of the study (i.e., safety and PK assessments) were affected by pretreatment. In addition, with only three and six patients having received darolutamide 300 and $600 \mathrm{mg}$, respectively, the sample sizes were too small to reliably demonstrate dose proportionality.

\section{Conclusions}

Darolutamide was well tolerated in heavily treated mCRPC Japanese patients up to $600 \mathrm{mg}$ BID, and no new safety signals were observed. There was no remarkable difference in 
PK between Japanese and Western patients. Exposures of darolutamide were increased with dose, with the PK of each dose appearing to be linear over time. Similar to the relative bioavailability observations in Western patient studies, darolutamide administered under fed conditions resulted in delayed absorption of the drug, with an increase in $C_{\max }$ and AUC compared with fasted conditions.

Acknowledgements Scientific writing support was provided by Alan J. Klopp, Ph.D., CMPP, at C4 MedSolutions, LLC (Yardley, PA), a CHC Group company, and funded by Bayer HealthCare Pharmaceuticals. Darolutamide was discovered at Orion Corporation and is being jointly developed with Bayer HealthCare Pharmaceuticals.

\section{Compliance with ethical standards}

Funding Bayer Yakuhin, Ltd. sponsored the study.

Conflict of interest Nobuaki Matsubara has received research funding from Bayer Yakuhin, MSD, Eisai, Sanofi, Taiho Pharmaceutical, Chugai Pharmaceutical, Janssen Pharmaceutical, Shionogi, Astellas, and Eli Lilly Japan. He has also received speaker honoraria from Bayer Yakuhin, MSD, AstraZeneca, Eisai, Ono Pharmaceutical, Sanofi, Takeda Pharmaceutical, Taiho Pharmaceutical, Novartis Pharmaceutical, Pfizer Japan, Merck Serono, and Janssen Pharmaceutical.

Hirofumi Mukai has received research funding from AstraZeneca, Eisai, Kowa, Taiho Pharmaceutical, Nippon Kayaku, Pfizer Japan, Glaxo Smithkline, Daiichi-Sankyo, Eli Lilly Japan, Parexel International, MSD, Ono Pharmaceutical, and Chugai Pharmaceutical. He has also received speaker honoraria from AstraZeneca, Eisai, Kowa, and Taiho Pharmaceutical. Ako Hosono has received research funding from Glaxo Smithkline, Yakult Honsha, Taiho Pharmaceutical, Nippon Kayaku, Novartis Pharmaceutical, Pfizer Japan, Kyowa Hakko Kirin, and Fujifilm RI Pharma. Mai Onomura and Masaoki Sasaki have no conflicts of interest to declare. Yoko Yajima, Kensei Hashizume, Masanobu Yasuda, and Miho Uemura are employees of Bayer Yakuhin, Ltd. Christian Zurth is an employee of Bayer AG.

Ethical approval All patients gave written informed consent for participation in the study. The study was approved by the study site's institutional review board (National Cancer Center Institutional Review Board, Japan) and conducted in accordance with the principles of the Declaration of Helsinki and the International Council for Harmonisation guideline E6: Good Clinical Practice and applicable regulatory requirements.

Open Access This article is distributed under the terms of the Creative Commons Attribution 4.0 International License (http://creativecommons.org/licenses/by/4.0/), which permits unrestricted use, distribution, and reproduction in any medium, provided you give appropriate credit to the original author(s) and the source, provide a link to the Creative Commons license, and indicate if changes were made.

\section{References}

1. World Cancer Research Fund International/Continuous Update Project (2015) Prostate cancer statistics. http://www.wcrf.org/ int/cancer-facts-figures/data-specific-cancers/prostate-cancerstatistics. Accessed 14 Feb 2017

2. Foundation for Promotion of Cancer Research (2014) Cancer statistics in Japan-2014. http://ganjoho.jp/data/reg_stat/statistics/
brochure/2014/cancer_statistics_2014_fig_E.pdf. Accessed 14 Feb 2017

3. Cancer Information Service, National Cancer Center. Vital Statistics in Japan. http://ganjoho.jp/en/professional/statistics/table download.html. Accessed 15 May 2017

4. Hori M, Matsuda T, Shibata A, Katanoda K, Sobue T, Nishimoto H, Japan Cancer Surveillance Research Group (2015) Cancer incidence and incidence rates in Japan in 2009: a study of 32 population-based cancer registries for the Monitoring of Cancer Incidence in Japan (MCIJ) project. Jpn J Clin Oncol 45:884-891

5. Sridhar SS, Freedland SJ, Gleave ME, Higano C, Mulders P, Parker C, Sartor O, Saad F (2014) Castration-resistant prostate cancer: from new pathophysiology to new treatment. Eur Urol 65:289-299

6. Lassi K, Dawson NA (2010) Update on castrate-resistant prostate cancer: 2010. Curr Opin Oncol 22:263-267

7. Kirby M, Hirst C, Crawford ED (2011) Characterising the castration-resistant prostate cancer population: a systematic review. Int J Clin Pract 65:1180-1192

8. Beer TM, Armstrong AJ, Rathkopf D, Loriot Y, Sternberg CN, Higano CS, Iversen P, Evans CP, Kim CS, Kimura G, Miller K, Saad F, Bjartell AS, Borre M, Mulders P, Tammela TL, Parli T, Sari S, van Os S, Theeuwes A, Tombal B (2017) Enzalutamide in men with chemotherapy-naive metastatic castration-resistant prostate cancer: extended analysis of the phase 3 PREVAIL study. Eur Urol 71:151-154. doi:10.1016/j.eururo.2016.07.032

9. Ryan CJ, Smith MR, Fizazi K, Saad F, Mulders PF, Sternberg CN, Miller K, Logothetis CJ, Shore ND, Small EJ, Carles J, Flaig TW, Taplin ME, Higano CS, de Souza P, de Bono JS, Griffin TW, De Porre P, Yu MK, Park YC, Li J, Kheoh T, Naini V, Molina A, Rathkopf DE, COU-AA Investigators (2015) Abiraterone acetate plus prednisone versus placebo plus prednisone in chemotherapy-naive men with metastatic castration-resistant prostate cancer (COU-AA-302): final overall survival analysis of a randomised, double-blind, placebo-controlled phase 3 study. Lancet Oncol 16:152-160. doi:10.1016/ s1470-2045(14)71205-7

10. Agarwal N, Di Lorenzo G, Sonpavde G, Bellmunt J (2014) New agents for prostate cancer. Ann Oncol 25:1700-1709

11. Leibowitz-Amit R, Joshua AM (2012) Targeting the androgen receptor in the management of castration-resistant prostate cancer: rationale, progress, and future directions. Curr Oncol 19:S22-S31

12. Pinto A (2014) Beyond abiraterone: new hormonal therapies for metastatic castration-resistant prostate cancer. Cancer Biol Ther 15:149-155

13. Fizazi K, Massard C, Bono P, Jones R, Kataja V, James N, Garcia JA, Protheroe A, Tammela TL, Elliott T, Mattila L, Aspegren J, Vuorela A, Langmuir P, Mustonen M, ARADES study group (2014) Activity and safety of ODM-201 in patients with progressive metastatic castration-resistant prostate cancer (ARADES): an open-label phase 1 dose-escalation and randomised phase 2 dose expansion trial. Lancet Oncol 15:975-985

14. Moilanen A, Riikonen R, Oksala R, Ravanti L, Aho E, Wohlfahrt G, Törmäkangas O, Kallio PJ (2013) ODM-201-new generation antiandrogen with excellent antiandrogenic and antitumor activity in nonclinical models of CRPC. Eur J Cancer 49:2869 (abstract)

15. Moilanen AM, Riikonen R, Oksala R, Ravanti L, Aho E, Wohlfahrt G, Nykanen PS, Tormakangas OP, Palvimo JJ, Kallio PJ (2015) Discovery of ODM-201, a new-generation androgen receptor inhibitor targeting resistance mechanisms to androgen signaling-directed prostate cancer therapies. Sci Rep 5:12007. doi:10.1038/srep12007

16. Fizazi K, Massard C, James ND, Culine S, Jones RH, Oksala R, Moilanen A, Aho E, Ravanti L, Kallio P (2013) ODM-201, a new generation androgen receptor inhibitor for castration-resistant 
prostate cancer: preclinical and phase I data. J Clin Oncol 31:65 (abstract)

17. Massard C, Penttinen HM, Vjaters E, Bono P, Lietuvietis V, Tammela TL, Vuorela A, Nykanen P, Pohjanjousi P, Snapir A, Fizazi K (2016) Pharmacokinetics, antitumor activity, and safety of ODM-201 in patients with chemotherapy-naive metastatic castration-resistant prostate cancer: an open-label phase 1 study. Eur Urol 69:834-840

18. Garcia JA, Kataja VV, James ND, Jones RH, Protheroe A, Massard C, Mattila L, Mustonen MVJ, Aspegren J, Fizazi K (2014) Bone and soft tissue response from a phase I/II study with ODM201 in metastatic castration-resistant prostate cancer (mCRPC). J Clin Oncol 32:102 (abstract)

19. Tammela L, Massard C, Bono P, Langmuir P, Aspegren J, Vuorela A, Mustonen MVJ, Fizazi K (2014) Safety and efficacy of ODM201 in chemotherapy and CYP17-inhibitor naïve patients: analysis of data from the ARADES and the ARAFOR trials. Eur Urol 13:e862 (abstract)

20. Scher HI, Halabi S, Tannock I, Morris M, Sternberg CN, Carducci MA, Eisenberger MA, Higano C, Bubley GJ, Dreicer R, Petrylak D, Kantoff P, Basch E, Kelly WK, Figg WD, Small EJ, Beer TM, Wilding G, Martin A, Hussain M, Prostate Cancer Clinical Trials Working Group (2008) Design and end points of clinical trials for patients with progressive prostate cancer and castrate levels of testosterone: recommendations of the Prostate Cancer Clinical Trials Working Group. J Clin Oncol 26:1148-1159

21. Eisenhauer EA, Therasse P, Bogaerts J, Schwartz LH, Sargent D, Ford R, Dancey J, Arbuck S, Gwyther S, Mooney M, Rubinstein L, Shankar L, Dodd L, Kaplan R, Lacombe D, Verweij J (2009) New response evaluation criteria in solid tumours: revised RECIST guideline (version 1.1). Eur J Cancer 45:228-247 